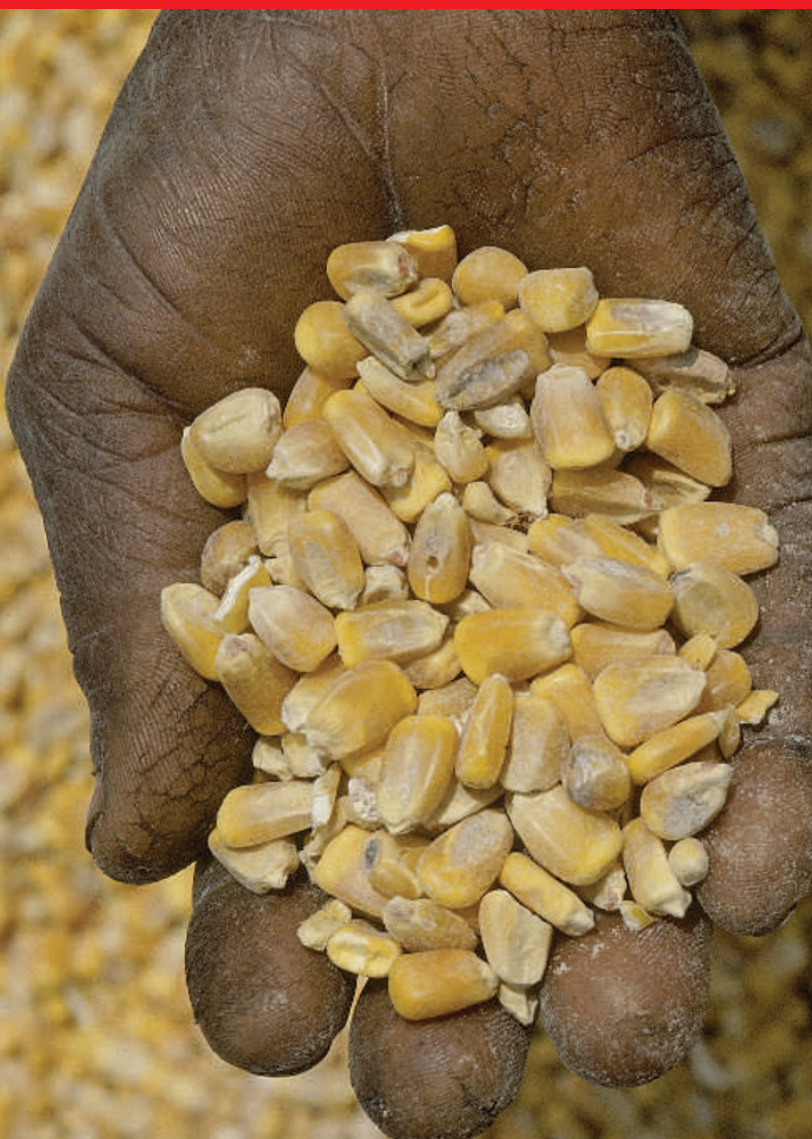

\title{
How to survive a warming world
}

\section{African communities have been adapting to climate change for millennia. Jim Giles reports on the strategies that seem most effective.}

Fis. our decades ago, drought arrived in El Fasher, an impoverished state capital in western Sudan. Rural communities there had relied on weak rains to raise crops in sandy soils. But rainfall has been below average ever since, displacing a million people in the area and forever altering the lives of many more.

Yet the people of El Fasher managed to adapt and survive. They built low earth embankments, known as trus, around their villages to hold water and irrigate crops of sorghum and vegetables. They developed new planting methods, digging through the layers of sand to the fertile ground beneath. And they introduced a wider range of crops, from citrus fruit to tobacco, both to broaden their food sources and to sell.

Today, El Fasher is facing a vastly different challenge, as it is at the heart of the bloody Darfur conflict. But elsewhere in the world, El Fasher's experience during drought should prove useful. Humans have adapted to changing environments for millennia, and many communities contain a wealth of knowledge about how to beat climatic odds and survive when rains fail or floods sweep away crops. So far, there have been few systematic studies of these survival strategies; but by tapping into communal knowledge, researchers are begin- ning to tease apart the actions that determine whether or not a community will make it in the face of change.

The process is formally known as 'adaptation', a term that is becoming a political buzzword even among environmentalists, who once saw it as a distraction from the business of cutting carbon dioxide emissions. Now, with climate change expected to have unprecedented effects on people worldwide (see page $706)$, adaptation can no longer be shunned (R. Pielke et al. Nature 445, 597-598; 2007). "People talk about adaptation as if it's a new invention," says Guy Jobbins, a senior pro-

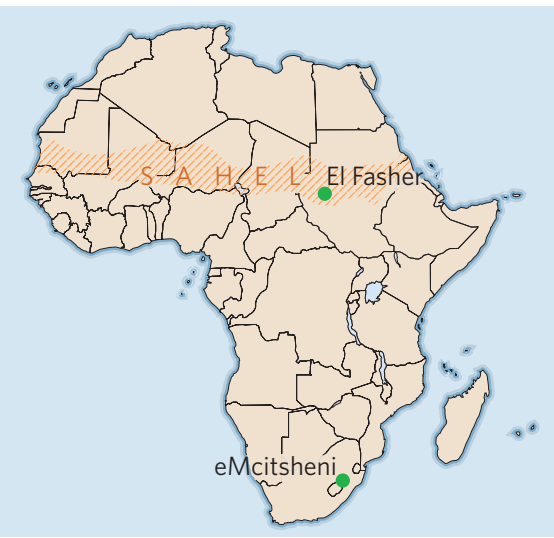

gramme officer at Climate Change Adaptation in Africa, a research organization based in Cairo. "It's not. People in Africa have been adapting for thousands of years."

It's not only Africa that will have to adapt, but the continent is often singled out because many of its residents live in precarious circumstances. In some countries, poor soils and a lack of government support already make many vulnerable to drought or extreme weather, so they have little to fall back on should climate change make things worse. Yet that is exactly what climate models predict is about to happen. "Drought and other climate disturbances exact an unacceptably high and reducible toll on the people of Africa, a toll that is likely to grow with climate change," says Balgis Osman-Elasha, a climate-policy expert at the Higher Council for Environment and Natural Resources in Khartoum, Sudan.

Africa's climate is poorly understood, in part because of patchy historical weather data. But the results that are available give cause for concern. The Sahara, for example, is expected to warm at rates greater than the global average of about $0.2{ }^{\circ} \mathrm{C}$ per decade during the early part of this century. Computer models also predict that eastern Africa will get wetter and see an increase in extreme rainfall events, and that 
parts of southern Africa will become drier.

Elsewhere on the continent, things are less certain. Richard Washington, an expert in African climate at the University of Oxford, UK, says that predictions are vague for El Fasher and the rest of the Sahel - the east-west band of semi-arid land between the Sahara and the greener landscape of central Africa.

This is partly because the thunderstorms of the monsoon are difficult to simulate in climate models. Capturing the effect of dust blown from the deserts of North Africa is another challenge the models struggle with. Consequently, says Washington, "you can get any result you like" with a climate simulation. If all models are averaged, a wetter future is predicted; if the selection is limited to those that closely simulate the current climate, the future looks drier than today.

\section{Changeable weather}

Data, and hence predictions, are better in South Africa, where some regions are already experiencing changes similar to those predicted by some of the better models. A team led by David Thomas, of the University of Oxford, has been studying the village of eMcitsheni, in the eastern part of the country, where rains have become more uncertain during the past 50 years. More heavy rainfalls have been arriving early in the wet season, before Christmas, and fewer at the tail end, around March.

Researchers can't say whether such changes are due to natural variability or rising carbon dioxide levels, but that matters little to the communities experiencing new weather patterns. Nor does it matter to those interested in understanding adaptation. As similar climatic changes are expected to occur in the future, villages in the region form a kind of natural laboratory in which to study the ongoing effects of climate change.

Several adaptation strategies are used at eMcitsheni, a rural area accessible only by dirt road that is home to about 300 households who depend on agriculture and livestock. Crops are planted farther apart so that more moisture is available for each row, increasing the likelihood that they will survive a period of drought. Corn (maize) varieties that mature faster have been brought in, again limiting the threat of dry spells. Local people have also set up a commercial cooperative: if the village produces excess maize in a certain year, the group works together to transport the crop to markets, earning money that can be used to buy food when yields are lower.

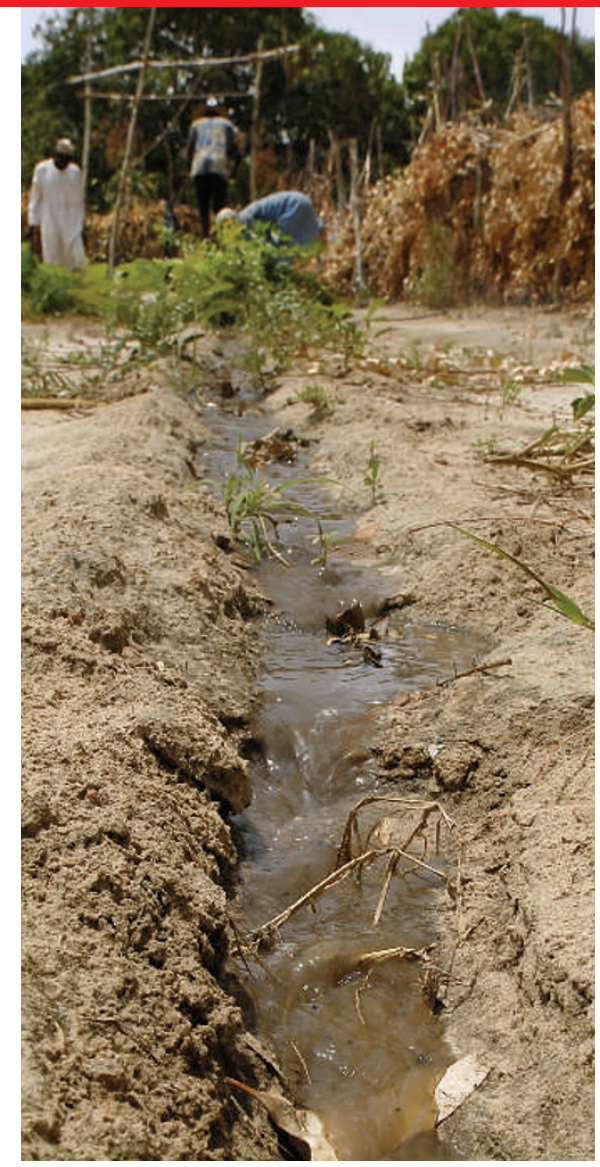

Different irrigation strategies have helped people in Africa's Sahel region survive persistent drought.

But would such strategies work in other places? Many development experts are cautious about extrapolating from small studies to broader rules about how communities in general should adapt. Climate is far from the only factor changing people's lives, and given the complexity associated with even simple changes, it is dangerous to think about a magicbullet solution to adaptation, says Jobbins.

Yet some general principles are starting to emerge. To that end, the Oxford team has studied three other rural communities in South Africa and Mozambique. All of these villages rely on crops and livestock, and all have seen substantial climate change during the past decade. In the Limpopo province, near the South African border with Zimbabwe, the wet season has started later over the past 50 years and included more dry spells. Further west, in the region near the town of Mafikeng, farmers have seen more rainy days early in the wet season, but more overall variability in rainfall between successive seasons.

In general, communities seem to have adapted best when working as a collective rather than as individuals. Overall, the team found four main strategies of adaptation: changes to agricultural practices; the formation of social networks; commercial projects, such as investing in livestock; and seeking work in distant areas. The first three of these strategies rely on people working together to better their community.

In eMcitsheni, for example, people developed communal horticultural projects. Local women created jointly run irrigated gardens that, because the risk was shared among the collective, allowed them to diversify into crops they might not have attempted to grow on their own, such as potatoes. When heavy rain damaged traditional corn plots, these gardens could help to compensate for what was lost. Surplus crops were sold and the proceeds invested in pumps.

Such sharing seems to work for many groups, says Henny Osbahr, a geographer at the University of Oxford. "It's complex," she says, "but we did see generic characteristics: strong informal institutions and networks of reciprocity."

Of course, many groups' ability to adapt is limited by factors beyond their control, such as lack of skills or money. Osman-Elasha has studied communities in El Fasher and other parts of Sudan, and says that various 'essential resources', such as access to spare machine parts, were cited repeatedly as problems by local people.

\section{Joining forces}

When communities work together they are better able to interact with outside organizations such as government agricultural officials and donor agencies. And several larger development agencies are making adaptation a formal part of what they do. The US Agency for International Development (USAID) in Washington DC, for example, has begun funding the introduction of rice varieties in southern Mali that are better suited to shorter rainy seasons, because farmers there have reported experiencing hotter and drier conditions in recent decades. USAID will release an adaptation handbook for all its programme officers this May; the World Bank is also developing adaptation information for its staff.

The agencies, along with local and national governments, face an enormous struggle. With wars, poverty and the AIDS epidemic, Africa is perhaps the region least well equipped to cope with climatic disturbances. The focus on building on local knowledge doesn't offer all the answers, but to adaptation experts it at least offers a way forwards.

"People felt that too much time spent on adaptation was taking attention away from doing something about the problem," says Emma Archer, a climate researcher at the University of the Witwatersrand in Johannesburg, South Africa. "That it was letting people off the hook. But now we know that we're committed to change. We're at an exciting stage."

Jim Giles is a senior reporter with Nature. 